\title{
DO COMPANIES ENGAGE IN MORAL GRANDSTANDING?
}

\author{
Cristina VOINEA ${ }^{a *}$, Radu USZKAI ${ }^{b}$ \\ ${ }^{a, b}$ Bucharest University of Economic Studies, Romania
}

\begin{abstract}
The main claim of our paper is that, if we agree that companies are (even in a loose sense) moral agents, then we can say that not only individuals engage in moral grandstanding. We will begin with a short introduction on what moral grandstanding means and the different ways in which we, as individuals, engage (both offline and online) in using moral talk for self-promotion. Afterwards, we will analyze what we consider to be the two of the most compelling cases of moral grandstanding by companies, greenwashing and ethics washing, highlighting their negative ethical consequences. The paper will end with a discussion of an additional reason which might explain why companies engage in moral talk through CSR campaigns: they do it not only because it pays off for them to look moral in front of their customers, but also due to the fact that grandstanding allows them to select better employees who might be willing to work more productively for lower wages.
\end{abstract}

KEYWORDS: moral grandstanding, greenwashing, ethics washing, Corporate Social Responsibility.

\section{INTRODUCTION}

It would be quite difficult to find a more paradigmatic figure who personifies the age of absolute monarchy than France's Louis XIV. Famously dubbed "the Great” and "the Sun King”, most of us have a visual grasp of him based on Hyacinthe Rigaud's famous 1701 painting. While we do not know what exact word people used in order to describe what the French king's pose, clothes and luxurious mise en scene were meant to convey, starting from the late $19^{\text {th }}$ century American English one word started to be used (first in baseball) that might have also been suitable for the famous king: the Sun King was "grandstanding" or, to put it more bluntly, he was showing of his power and opulence. While the term "grandstanding" became more popular starting from the '70's, being used in a wide variety of contexts, it is not solely reserved for Early Modern European monarchs: football players enjoy grandstanding both on and off the pitch, while pop stars like to show off their wealth and tattoos. Some might even argue that grandstanding is not even something that only humans engage in (just think about the classical example of a peacock strutting his tail).

In their recent work, Justin Tosi and Brandon Warmke argue that, while grandstanding seems to be a pervasive behavior across species, there is one type of "showing off" that is specifically human: moral grandstanding.

The aim of our paper is that of extending the framework developed by Tosi and Warmke in order to argue that not only individuals, but also companies engage in moral grandstanding. Before going over the plan of our paper, we need to make explicit one implicit assumption of our research: there is at least a minimal sense in which we can talk about group/collective moral agency in the case of business corporations (List \& Pettit, 2011; Hess, 2014).

\footnotetext{
*Corresponding author. E-mail address: cristina.voinea@man.ase.ro
} 
The first objective of our paper will be that of presenting a short overview of what Tosi and Warmke mean when they talk about grandstanding as the "use of moral talk for self-promotion" (2020a, 40), of the various ways in which individuals do it (either online or offline) and some of the reasons why they believe that doing it raises serious moral concerns. We will then proceed to present two of the most relevant cases in which we argue that companies use moral talk for self-promotion: when they are involved in greenwashing and ethics washing.

Last but not least, starting from recent empirical work done by List et al. (2019), we propose a novel way of understanding why companies engage in ethically loaded CSR campaigns and how Milton Friedman's classical take on the social responsibility of companies could be reframed in the wake of these ideas.

\section{WHAT IS MORAL GRANDSTANDING?}

The relevant starting point for understanding what moral grandstanding consists in is the formula proposed by Tosi and Warmke (2020, 15):

$$
\text { Grandstanding = Recognition Desire }(R D)+\text { Grandstanding Expression (GE) }
$$

On the one hand, $\mathrm{RD}$ consists in the fact that the individual who is involved in grandstanding has the following (intermediate) goal: she wants to impress others with her moral qualities. As such, she might want others to perceive her either as a moral saint, a decent individual or as someone who is worthy of moral praise and admiration. Furthermore, the key to understanding RD has to do with the fact that moral praiseworthiness and admiration are essential for acquiring prestige and dominance (Grubbs et al. 2019). What grandstanders want, ultimately, is to "elevate their status [and] silence others and create fear" (Tosi \& Warmke, 2020a, 17). GE, on the other hand, refers to the various ways in which we attain RD. Presently, we do most of our moral talk online, on various social media platforms. Depending on the context, enclosing a hashtag like \#BlackLivesMatter or \#AllLivesMatter to your Facebook or Twitter posts could count as moral grandstanding. Likewise, dispersing a peaceful crowd protesting in front of the White House just in order to make a photo of yourself holding a Bible in front of a church still counts as moral grandstanding, even if no actual speech was involved and the event happened offline (and you are an American president trying to appeal to Republican voters from the Bible Belt).

Tosi and Warmke (2016, 203; 2020a, 45 - 64) further distinguish between five ways in which we morally grandstand (either online or offline). Sometimes, people simply want to signal the fact that they are on the right side of an ethical debate and they publicly profess their agreement with what something someone previously said. This is what the two philosophers labeled as "piling on". Other times, when we want to show off during a heated debate with moral implications, we just "ramp up" our accusations to the other moral tribe: the end purpose is not necessarily that of winning the debate though logic and arguments, but to outdo the other person with our rhetorical skills. "Trumping up" is another strategy used by moral grandstanders: we make "spurious moral complaints" (2020a, 55) in moral debates and object to some aspects of our moral world that some people might not find as significant or problematic. Last but not least, moral grandstanders sometimes use emotionally loaded words ("excessive emotional display") and dismiss the moral weltanschauung of others ("claims of self-evidence”).

Moral grandstanding is not necessarily bad. As Tosi and Warmke argue, using moral talk for selfpromotion is quite a cheap and effective way of signaling to the members of your moral tribe that you are a trustworthy individual. It also has another positive consequence, one which might even be quantifiable: if we are motivated by the strong moral emotions displayed in online moral talk, we might end up "rage-giving" to certain charities. However, leaving aside these benefits, they argue that an objective overview of the consequences of moral grandstanding should convince us that, on 
average, moral self-promotion leads ultimately to sub-optimal consequences and imposes problematic social costs. According to Tosi and Warmke, moral grandstading is strongly related to an increase of political polarization (leading people to fall pray more often to confirmation bias), cynicism (it leads people to think that moral talk is superfluous and trivial) and increases the occurrence of outrage exhaustion (the more we hear people expressing their outrage regarding a particular moral flaw, the less will we be able to use outrage as an effective tool in the future in the face of real danger). Additionally, moral grandstanding is also a threat to free expression, as the prevalence of moral grandstanders in a particular moral narrative might lead to people be less prone to investigate those popular ideas and, thus hampering our desire to finding the truth (Tosi \& Warmke, 2020b).

Is RD specifically human? Are humans the only ones able to employ a GE? Our hypothesis is that the framework advanced by Tosi and Warmke has he necessary versatility in order to shed light on what companies do when they engage in moral talk, either through CSR or Corporate Social Advocacy (CSA) campaigns. Just take the example of the American fast-food chain Chick-fil-A, famous for opposing marriage equality, gun control and reproductive rights (Dodd \& Supa 2015). Likewise, most of us remember the famous video championed by Gillette in the midst of the \#metoo movement tackling toxic masculinity (Bogen et al., 2020). Last but not least, who can forget the famous Pepsi ad featuring Kendall Jenner taking part in a Black Lives Matter inspired protest (Dozé, 2018)? Why would companies pile on, tramp up or display excessive emotional reactions like this? Long story short: for the same reason that individuals do it.

\section{TWO CASES OF USING MORAL TALK FOR SELF-PROMOTION: GREENWASHING AND ETHICS WASHING}

\subsection{Greenwashing as a form of moral grandstanding}

Climate change is one of the biggest challenges current and future generations will have to confront and manage. Given that the subject of climate change is of interest for both consumers and political representatives, companies are trying to capitalize on this topic. More specifically commercial organizations invest more and more time, energy and money in advertisement and CSR campaigns meant to promote an environmentally friendly image. In other words, companies are trying to advertise their products, services or even themselves as "green", in order to attract the growing segment of environmentally aware consumers. But there is a growing gap between what companies claim they are selling or producing, and what they are actually commercializing or putting on the market. Most of the claims companies now make pertaining to their green production or products are misleading or in some cases plain false. As a result, the term "greenwashing" has been popularized by ethicists, in order to name the phenomenon of publicizing and presenting to the public false or misleading information by an organization for the purpose of painting in the public eye an environmentally responsible public image (Laufer, 2003). Greenwashing emerges out of the juxtaposition of two types of firm behaviors: a poor track record in environmental performance and a positive communication strategy regarding the company's environmental performance (Delmas and Burbano, 2011).

One of the most known examples of greenwashing is Ford Motor Company's campaign, employing Kermit the Frog, a well-known fictional character from the Muppets, who sang "It Isn't Easy Being Green" in advertisements promoting the hybrid Escape SUV as a "green" alternative to most vehicles on the market. The campaign backfired when consumers found out that despite Ford's claims that the Escape model was environmentally friendly, the model was actually one of the worst carbon emitters and had the worst fuel efficiency trends amongst all cars available on the market (Furlow, 2010). Since the public scandal surrounding Ford's misleading claims erupted, the company put an end to all campaigns depicting the company's products as environmentally friendly. A similar scandal, coined "Dieselgate", erupted in connection to Volkswagen, who 
marketed its diesel cars as environmentally friendly, despite the diesel engines emitting up to 40 times more pollutants than the allowed threshold within the US (Hotten, 2015). These are just two fortunate examples where the practice of greenwashing was exposed to the public and customers were compensated for having been plainly misled by the famous automakers.

Besides the fact that greenwashing misleads consumers, a phenomenon that is not so new in the advertisement and CSR landscapes (Jahdi and Acikdilli, 2009), what other harms does it produce? First and foremost, when everything is touted as "green", without actually being so, such claims become meaningless to consumers. Whether companies like it or not, almost every year there is a global scandal concerning products advertised as green which are not actually environmentally friendly. Through these types of public scandals, the public became aware of practices of greenwashing. As such, when most companies engage in greenwashing, they affect not only the consumers who are lied to or misled, but they also negatively impact those organizations which are actually true to their environmental mission. The latter might lose their competitive edge due to the fact that consumers are aware that most companies pretending to be green are not actually that environmentally friendly, thus their trust in the claims of "environmental friendliness" of different services and products is declining (Chen and Chang, 2013). In the end, this situation contributes to the confusion amongst citizens regarding what products or services actually contribute to the health of the environment. When confusion reigns between customers and companies become aware of this, it disincentivizes organizations to actually create and develop green products and services, given that customers will simply discount them (Furlow, 2010). As a consequence, greenwashing affects not only consumers and organizations that actually try to be more environmentally aware, but also the environment in itself. This is due to the creation of a context where consumers tend to deem all environmental claims as false, thereby plainly avoiding or ignoring products and services advertised or presented as safe for the environment.

Our claim is that greenwashing is a type of moral grandstanding, through which companies paint themselves as superior to other organizations regarding their environmental policies. Companies will use greenwashing to signal that the firm is a good corporate citizen, because they will benefit from making stakeholders aware of their "good" performance. Moreover, companies have all the incentives to engage in greenwashing because they seek to convince employees, as well as external stakeholders, of the organization's commitment to ethics. It is more cost efficient to just signal your ethical virtues, than to actually implement them. When companies practice greenwashing, they are actually not aiming at promoting environmental causes, but they are only seeking to improve or even enhance their status or to promote themselves by making use of moral talk regarding the environment.

\subsection{Ethics washing as a form of moral grandstanding}

Artificial Intelligence is increasingly present in various area of human activity, having the potential to radically change human decision making and improve people's lives. But, as the governance frameworks for AI and algorithmic decision-making are yet to be developed, the use of such sophisticated and ever more complex technologies is not without risks. Problems are likely to arise in data collection and sorting, discrimination due to biased data fed into the algorithms, uncertainty regarding the attribution of moral responsibility in cases where something goes wrong and so on. A case that exemplifies the threat of current AI systems is their increasing use in decision-making processes. More and more, algorithms are used not only to sift through huge amounts of data and categorize individuals, but also to derive conclusions and carry out decision-making that significantly impacts people's lives (O’Neil, 2016). Algorithms underlying AI—in particular, machine learning algorithms - are increasingly ruling our lives. They filter candidates for employers, carry out personalized pricing, decide what ads to show to individual Internet users, assess loan applications, buy and sell stocks, and more (Pasquale, 2015). In some cases, algorithms use seemingly arbitrary or unfair criteria to make these decisions. What is more problematic is that 
algorithms are protected by intellectual property, which makes them unaccountable for the large public. But these algorithms become even more problematic form a moral standpoint when they become so complex and self-modifying that they are impenetrable even to the programmers who have created them.

As such, many companies working with AI, from Google, to Facebook or Uber, have created their own teams and committees of experts dealing with the ethical issues stemming from the use of their products as a way to mitigate the potential risks that might arise (Bietti, 2019). All in all this should be good news for everyone interested in developing ethical technologies; but, once again, ethics is mostly used as a means to signal to the public and also to regulators tech companies' commitment to ethical principles, while in fact using ethics as an "elegant public decorations” (Metzinger, 2011) meant to push companies' interest while avoiding regulation.

The term "ethics washing” (Wagner, 2018) has been put forth in order to describe companies' appeal to ethics as a means to avoid regulation and to paint themselves in a more positive light regarding their awareness of the potential ethical harms stemming from the creation and use of new technologies. In other words, ethics washing arises whenever "a company is actively engaged in various ethics partnerships but doesn't act on it and isn't held accountable” (Bietti, 2019).

For example, in 2019 Google set up an advisory committee with the purpose of developing responsible and sustainable AI. One of the board members was an active anti LGBT advocate who also happened to have strong connections to the United Stats's very controversial president of the time, Donald Trump (Levin, 2019). When the news of the board composition broke loose, both Google employees and consumers at large started a petition asking for the removal of this dubious member from the ethical committee, stating that "Google is making clear that its version of 'ethics' values proximity to power over the wellbeing of trans people, other LGBTQ people and immigrants." (Levin, 2019). After almost two weeks, due to the public outcry, the council was indefinitely disbanded. This is just one example of the instrumentalization of ethics for the purpose of creating a better public image and avoiding regulation. Moreover, companies such as Google employ moral philosophers in order to inform the design of new products and services and they also shifted their production processes towards more humane technologies (which supposedly respect the privacy and attention of users) (Bietti, 2019). Unfortunately, this heavy use of ethical instruments (such as ethical committees, codes of conduct, and experts) have little leverage in shaping or changing the companies' organizational culture and are more likely to be simple publicity stunts.

Just like greenwashing, ethics washing is the attempt of tech companies to signal to the public but also to regulators that they are aware of the ethical implications of their products and that they are striving to do something about them, although these efforts are not undertaken in good faith. This is due to the fact that most self-regulatory ethical measures such as the ones described above are subjected to internal limits and are largely dependent on companies' funding, which might restrict or affect the strength and substance of the outcomes reached through them (Bietti, 2019).

\section{FURTHER IMPLICATIONS AND CONCLUDING REMARKS}

Our paper showed that moral grandstanding is not something specifically human, but that we can extend the framework advanced by Tosi and Warmke to include collective moral agents like corporations. Future work might extend this framework even further, to other such collective entities, be they NGO's or even governments.

When talking about moral grandstanding in the case of companies, we found greenwashing and ethics washing as two particularly interesting examples to explore due to the implications of such CSR and CSA campaigns. There is one additional implication of companies being involved in their self-promotion through the use of moral talk that we saved for last. We generally tend to think that CSR campaigns are generally addressed either to the general public and consumers. More recently, 
as we previously mentioned, such campaigns might even be designed to signal something to public regulators.

However, recent research from List et al. $(2019,2)$ suggests something quite surprising: the found "strong evidence that when a firm advertises work as socially-oriented, it attracts employees who are more productive, produce higher quality work, and have more highly valued leisure time. In terms of enhancing the labor pool, for example, CSR increases the number of applicants by 25 percent, an impact comparable to the effect of a 36 percent increase in wages”. It seems that companies engage in CSR campaigns using explicit moral talk not only because it pays off for them to look moral not only when regulators and customers are looking, or in comparison to their competitors, but also (maybe more importantly?) because it allows them to select better employees who might be willing to work more productively for lower wages. If future empirical research will prove List et al. to be right, then it seems that, if some believes that the only social responsibility of business is to increase its profits (Friedman, 1970), the use of moral talk for self-promotion is something that management should employ. The problems that both Tosi and Warmke's work and ours highlight still need to be addressed, however.

\section{REFERENCES}

Bietti, E. (2019). From Ethics Washing to Ethics Bashing: A View on Tech Ethics from Within Moral Philosophy. SSRN Scholarly Paper ID 3513182. Rochester, NY: Social Science Research Network.

Bogen, K. W., Williams, S. L., Reidy, D. E., \& Orchowski, L. M. (2020). We (want to) believe in the best of men: A qualitative analysis of reactions to \#Gillette on Twitter. Psychology of Men \& Masculinities. doi: 10.1037/men0000308.

Chen, Y. \& Chang, C.-H. (2013). Greenwash and Green Trust: The Mediation Effects of Green Consumer Confusion and Green Perceived Risk. Journal of Business Ethics 114 (3): 489-500.

Delmas, M. A. \& Burbano, V. C. (2011). The Drivers of Greenwashing. California Management Review 54 (1), 64-87.

Dodd, M. D. \& Supa, D. (2015). Testing the Viability of Corporate Social Advocacy as a Predictor of Purchase Intention. Communication Research Reports, 32 (4), 287-293.

Hotton, R. (2015, December 10). Volkswagen: The Scandal Explained. BBC News. Retrieved 10 December, 2015, from https://www.bbc.com/news/business-34324772.

Dozé, M. (2018). Misreading the Rhetorical Situation: An Analysis of the Kendall Jenner Pepsi Commercial. Young Scholars in Writing, 15, 116-122.

Furlow, N. E. (2010). Greenwashing in the New Millennium. The Journal of Applied Business and Economics 10 (6), 22-27.

Friedman, M. (1970, September 13). The social responsibility of business is to increase its profits. New York Times Magazine.

Grubbs, J. B., Warmke, B., Tosi, J., James, A. S., \& Campbell, W. K. (2019). Moral grandstanding in public discourse: Status-seeking motives as a potential explanatory mechanism in predicting conflict. PLoSONE 14 (10):e0223749. https://doi.org/10.1371/journal.pone.0223749.

Hess, K. M. (2014). The Free Will of Corporations (and Other Collectives). Philosophical Studies 168 (1): 241-260.

Jahdi, K. S. \& Acikdilli, G. (2009). Marketing Communications and Corporate Social Responsibility (CSR): Marriage of Convenience or Shotgun Wedding? Journal of Business Ethics 88 (1): 103-13.

Laufer, W. S. (2003). Social Accountability and Corporate Greenwashing. Journal of Business Ethics 43 (3), 253-61. 
Levin, S. (2019, April 5). 'Google Scraps AI Ethics Council after Backlash: "Back to the Drawing Board"'. The Guardian. Retreieved 5 April, 2019 from http://www.theguardian.com/technology/2019/apr/04/google-ai-ethics-council-backlash.

List, C. \& Pettit, P. (2011). Group Agency: The Possibility, Design, and Status of Corporate Agents. New York: Oxford University Press.

List, J. A. et al. (2019). Toward an Understanding of Corporate Social Responsibility: Theory and Field Experimental Evidence. NBER Working Papers Series, Working Paper 26222. Retrieved 9 May, 2020 from http://www.nber.org/papers/w26222.

Metzinger, T. (2011, April 8). Ethics washing made in Europe. Der Tagesspiegel. Retrieved 16 November, 2020 from https://www.tagesspiegel.de/politik/eu-guidelines-ethics-washing-madein-europe/24195496.html.

O’Neil, C. (2016). Weapons of Math Destruction: How Big Data Increases Inequality and Threatens Democracy. New York: Crown.

Pasquale, F. (2015). The Black Box Society: The Secret Algorithms That Control Money and Information. Harvard: Harvard University Press.

Tosi, J. \& Warmke, B. (2020a). Grandstanding. The use and abuse of moral talk. New York: Oxford University Press.

Tosi, J. \& Warmke, B. (2020b). Moral Grandstanding as a Threat to Free Expression. Social Philosophy and Policy, 37 (1), 1-22.

Wagner, B. (2018). Ethics as an Escape from Regulation: From Ethics-Washing to EthicsShopping. In M. Hildebrandt (Ed.), Being Profiling. Cogitas ergo sum, (pp. 1-7). Amsterdam, Amsterdam University Press. 